\title{
Recent advancement on technical requirements for grid integration of wind power
}

\author{
Xiaoge LIU, Zhao XU ( $ه)$, Kit Po WONG
}

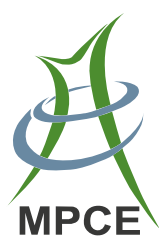

\begin{abstract}
The installation of wind energy has experienced rapid development during recent years. As a result, the operation of power system can be greatly affected. Therefore, the operators of different countries have formulated the grid codes which reinforce technical requirements for wind power plants. In this paper, recent grid codes published in different countries have been carefully reviewed. The basic requirements of active power control and reactive power compensation, both of which have particular influence on wind power plants operation, are focused on. Based on this review, it is understood that with the increasing integration of wind energy, there is a worldwide trend to regulate the performance of wind power plants so that they can contribute to the stability and reliability of power system.
\end{abstract}

Keywords Wind power, Grid integration requirements, Low voltage ride through, Active power control

\section{Introduction}

Considering the increasing public awareness of energy crisis, renewable energy such as wind and solar energy have gained rapid development globally. During the past 15 years, the commercial installation of wind energy has increased continuously $[1,2]$.

Received: 27 September 2013/ Accepted: 31 October 2013/ Published online: 6 December 2013

(C) The Author(s) 2013. This article is published with open access at Springerlink.com

X. LIU, Z. XU, The Hong Kong Polytechnic University, Hung Hom, Hong Kong

( $₫)$ e-mail: eezhaoxu@polyu.edu.hk

K. P. WONG, The University of Western Australia, Crawley, WA 6009, Australia
Wind energy proved to be clean without $\mathrm{CO}_{2}$ emission. However, due to the stochastic nature of wind, the characteristics of the power generated by wind turbines (WTs) are quite different from that provided by conventional generators. Consequently, the stability and reliability of the whole power system can be influenced by the increasing penetration level of wind power $[3,4]$. In order to minimize the adverse impact of wind energy, the performance of wind power plants (WPPs) should be regulated.

For the conventional power plants (CPPs), which mainly consist of thermal synchronous generators, the operation principles have been well-established. The implementation of these principles regulates the behaviors of CPPs and takes the advantages of synchronous generators to ensure the stability of the power system.

Based on the existing technical regulations for CPPs, the grid codes, which provide basic requirements for WPPs, have been published by the transmission system operators (TSOs) in recent years. It is expected that WPPs can be similar in performance to CPPs [5].

According to these grid codes, the wind power plants should participate in frequency control and voltage control under normal conditions [5-8]. In the event of voltage drop, the requirements of Low Voltage Ride Through (LVRT) and supply of reactive power have been reinforced $[5,6]$. As the contribution from wind power generation becomes increasingly larger, these grid codes may be revised and enhanced in the future [5].

For manufacturers and researchers, the grid codes can be regarded as important guide-lines for the development of WT techniques [6]. In recent years, many control schemes aiming at satisfying the grid codes requirements have been proposed. Several promising methods for frequency control have been provided in $[7,9,10]$. In addition, some LVRT strategies for individual WT have been developed in [11-13]. 
Table 1 Grid codes published in different countries

\begin{tabular}{llll}
\hline Country & TSO & $\begin{array}{l}\text { Issue } \\
\text { year }\end{array}$ & Refs \\
\hline Denmark & Energinet.dk & 2009 & {$[15]$} \\
Germany & TenneT & 2012 & {$[16]$} \\
Canada & Aeso & 2013 & {$[17]$} \\
Ireland & EirGrid & 2012 & {$[18]$} \\
China & State Grid Corporation of China & 2009 & {$[19]$} \\
& (SGCC) & & \\
& & &
\end{tabular}

In this paper, the grid codes listed in Table 1 are reviewed $[4,5,14]$. Due to the rapid development of wind energy in the listed countries, these grid codes are considered to be representative. Detailed requirements of these grid codes have been discussed in Section 2 and Section 3. Specifically, the principles on active and reactive power control under normal operation are compared in Section 2. Also, the basic requirements in abnormal condition are analyzed in Section 3.

\section{Requirements of performance under normal condition}

\subsection{Active power control}

The requirements of active power control concern about the performance of active power output provided by WPPs. Traditionally, WPPs are simply required to generate active power as much as possible [20]. However, since the penetration level of wind energy has grown rapidly, TSOs formulate various control functions of active power such as frequency control and power gradient limit, which must be implemented [20].

Frequency control refers to the capability to participate in frequency stabilization. For WPPs, TSOs have determined their own frequency variation that the WPPs should tolerate. Figures 1-3 shows the detailed requirements of frequency control in Denmark and Germany. In Denmark, the normal range of frequency is between 49.5 and $50.2 \mathrm{~Hz}$ [15]. While in Germany, the normal variation of frequency is $49.00-50.5 \mathrm{~Hz}$ [16]. As for active power control, all the grid codes demands that the active power production should be adjustable in the event of the small deviation of frequency. In Germany, as Fig. 2 shows, active power provided by WPPs can be decreased only when frequency becomes higher than $50.2 \mathrm{~Hz}$ [16]. Figure 3 is the droop requirements of frequency response in Denmark, in which $\mathrm{f} 2$ and $\mathrm{f} 3$ are the boundaries of dead band. When frequency varies between $\mathrm{f} 1$ and $\mathrm{f} 4$, primary control for frequency should be implemented [14, 15]. Besides, the duration and

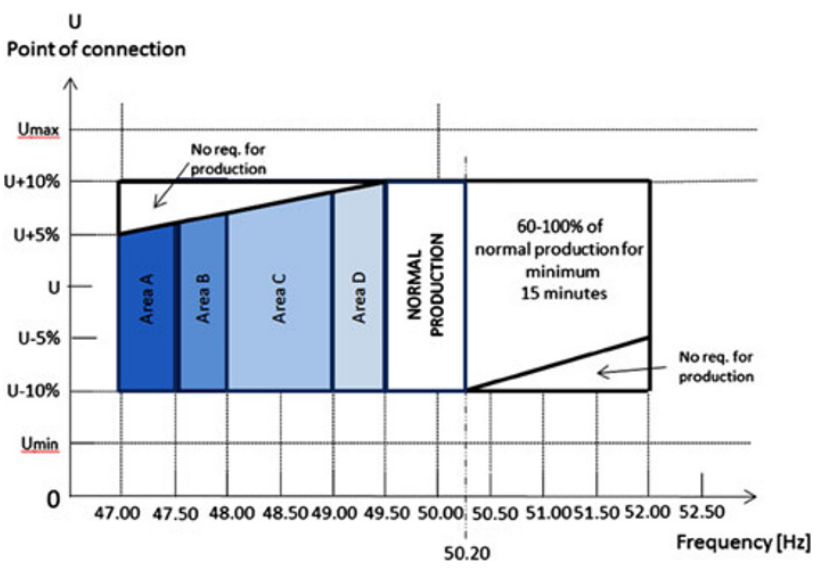

Fig. 1 Active power production requirements in Denmark [15]

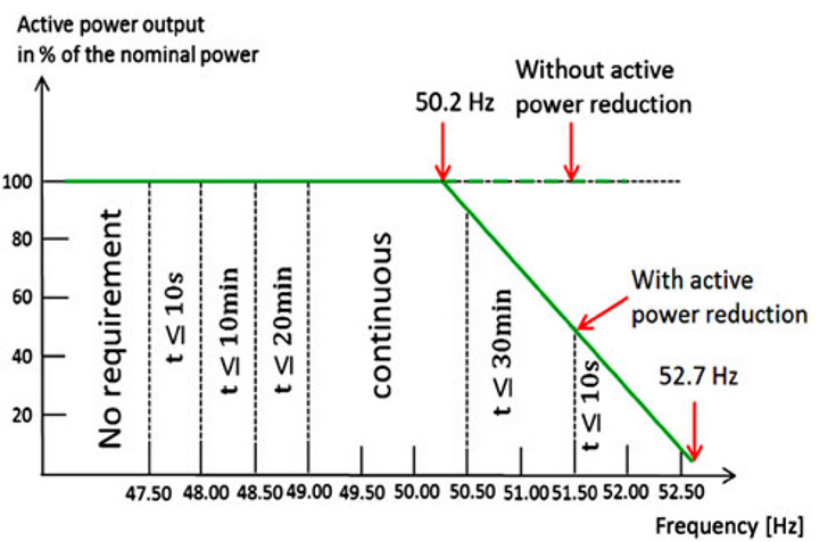

Fig. 2 Basic requirements for the active power output of a generation unit in German grid code [16]

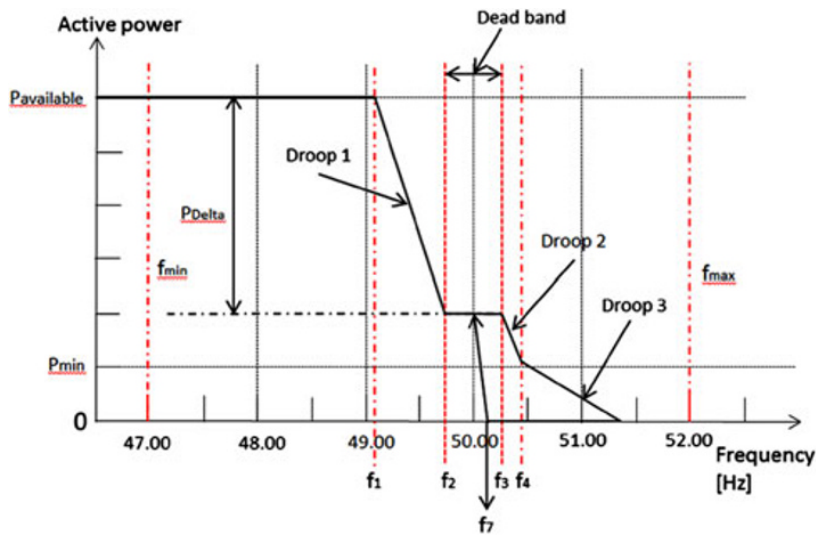

Fig. 3 Frequency control for wind power plants with a power output higher than $25 \mathrm{MW}$ in Danish grid code [15]

accuracy of frequency control function have been regulated in Danish grid codes. Moreover, the Danish grid code, which includes the most specific requirements on active power control herein, demands WPPs should regulate the active power output considering the voltage of point of connection (POC) as well as frequency. 
Table 2 Requirements of active power control for frequency stabilization in Canada [17]

\begin{tabular}{ll}
\hline Frequency $(\mathrm{Hz})$ & Minimum time delay \\
\hline$>61.7$ & $0 \mathrm{~s}$ \\
61.6 to 61.7 & $30 \mathrm{~s}$ \\
60.6 to $<61.6$ & $3 \mathrm{~min}$ \\
$>59.4$ to $<60.6$ & Continuous \\
& Operation \\
$>58.4$ to 59.4 & $3 \mathrm{~min}$ \\
$>57.8$ to 58.4 & $30 \mathrm{~s}$ \\
$>57.3$ to 57.8 & $7.5 \mathrm{~s}$ \\
$>57.0$ to 57.3 & $45 \mathrm{cycles}$ \\
$\leq 57.0$ & $0 \mathrm{~s}$ \\
\hline
\end{tabular}

Table 3 Constraints of active power output in Chinese grid code [19]

\begin{tabular}{lll}
\hline $\begin{array}{l}\text { The installed capacity of } \\
\text { wind farm (MW) }\end{array}$ & $\begin{array}{l}10 \text { min maximum } \\
\text { ramp rate (MW) }\end{array}$ & $\begin{array}{l}1 \text { min maximum } \\
\text { ramp rate }(\mathrm{MW})\end{array}$ \\
\hline$<30$ & 10 & 3 \\
$30-150$ & Installed capacity/3 & $\begin{array}{c}\text { Installed capacity/ } \\
10\end{array}$ \\
$>150$ & 50 & 15 \\
\hline
\end{tabular}

Similarly, the grid codes published in China, Ireland and Canada have established their own frequency boundaries for continuous operation [17-19]. In China, the WTs should operate continuously when frequency varies from 49.5 to $50.2 \mathrm{~Hz}$ [19]. The normal operation range in Ireland is $49.5-51.0 \mathrm{~Hz}$ [18]. It is necessary to point that the nominal frequency in the selected Canadian grid code is $60 \mathrm{~Hz}$ [17]. The details of Canadian requirements have been illustrated in Table 2 [17].

Furthermore, considering the deviation of frequency indicates the imbalance between the supply and demand of active power, WPPs are required to operate with a certain reserve capacity $[4,20]$. The reserve power can be utilized for frequency stabilization [4, 20]. Besides, some papers proposed various strategies which recommend that the inertial energy stored in the rotor of WT can be exploited temporarily to participate in primary frequency control $[7$, $9,10]$.

Power gradient limit determines the constraints of ramp rate to avoid frequency deviation, especially when active power provided by WPPs varies rapidly [21]. The specific requirements have been formulated by TSOs. In China, the recommended constraints of active power production have been listed in Table 3 [19]. The gradient limit in Ireland can be varied between 1 and 30 MW per minute [18]. Such requirements should consider the characteristics of conventional power plants so that the active power supply of the whole system can keep steady [20].
For individual wind turbine, the active power can be fluctuating when wind changes rapidly. To prevent the fluctuation of power and smooth the production, energy storage devices such as batteries and capacitors can be installed [22]. In addition, some coordinated control strategies such as adjusting pitch angle or controlling the DClink voltage have been proposed [22, 23].

The frequency control and power gradient limit may be in conflict with the capture of wind energy, such as maximum power point tracking (MPPT) control. Consequently, the operation of WTs can be influenced. For one certain wind farm with centralized controllers, both the wind condition and the situation of each WT should be taken into account so that the reference signal generated by the centralized controllers can be appropriately dispatched to each WT [20]. Moreover, some autonomous control schemes, which are alternative for WPPs, are required to be developed further.

\subsection{Reactive power control}

Reactive power control concerns the stability of voltage [24]. In the selected grid codes, the requirements of reactive power control are often illustrated by power factor curves [24]. Particularly, a bonus or penalty regulation based on the variation of power factor has been established in Spain [25].

To formulate the requirements of reactive power control for WPPs, the technical characteristics of individual WT should be considered. In the 1990s, fixed-speed wind turbines (FSWTs) were widely installed [26, 27]. However, the induction generator equipped in FSWT can absorb reactive power from the power grid [27]. As a result, the reliability of power system can be decreased, especially when grid faults occur. Moreover, FSWT can hardly control the output of reactive power [27]. Therefore, such WTs cannot contribute to the stabilization of grid voltage automatically. Therefore, TSOs simply formulated general operating constraints of power factor for WPPs [24]. The Danish grid code published in 2000 even required that WPPs should operate with unity power factor [24, 28]. To fulfill these requirements, capacitor banks are required for reactive power compensation $[26,27]$.

Since 2001, DFIG has been a dominant type in industry [2, 26, 27]. For individual DFIG, rotor side converter, grid side converter and DC-link capacitor should be equipped. Hence, it is possible that generator in DFIG can be excited by controlling rotor side converter without absorbing reactive power from power grid [27]. Furthermore, the installed capacitor and converters can be used to provide reactive power for voltage stabilization.

Due to the development of WT techniques, the grid codes published recently formulate more control functions 


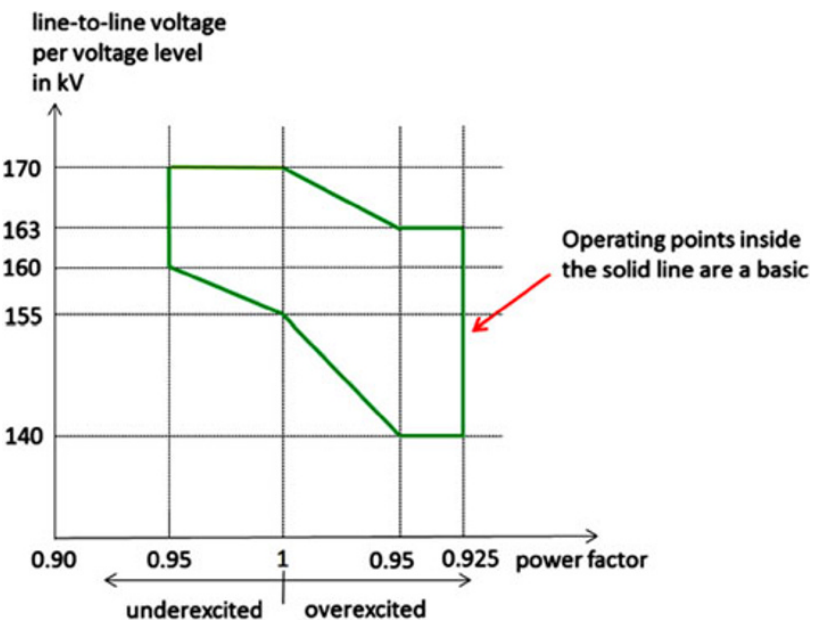

Fig. 4 Operation range of WPPs in Germany [16]

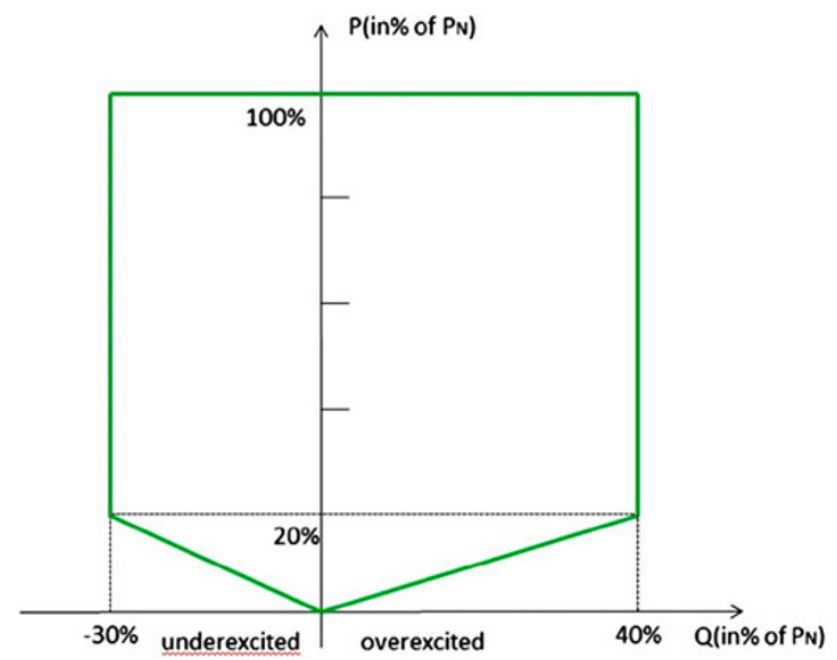

Fig. 5 Operation range of individual wind turbine in Germany [16]

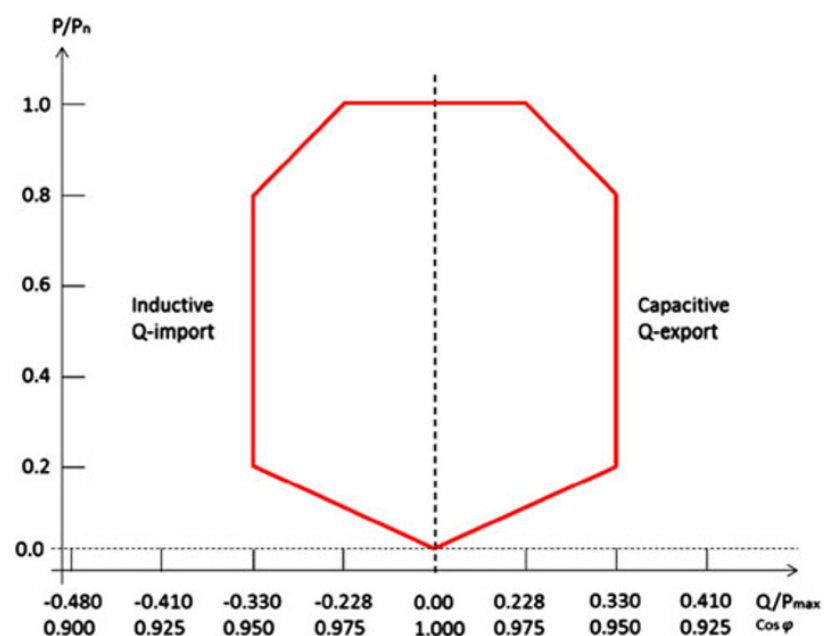

Fig. 6 Operation range of WPPs in Denmark [15]
Table 4 Range of power factor in Canada, Ireland and China [1719]

\begin{tabular}{lll}
\hline TSO & Country & Power factor range \\
\hline AESO & Canada & -0.95 to 0.9 [17] \\
EirGrid & Ireland & 0.85 lagging to 0.85 leading [18] \\
SGCC & China & 0.95 lagging to 0.95 leading [19] \\
\hline
\end{tabular}

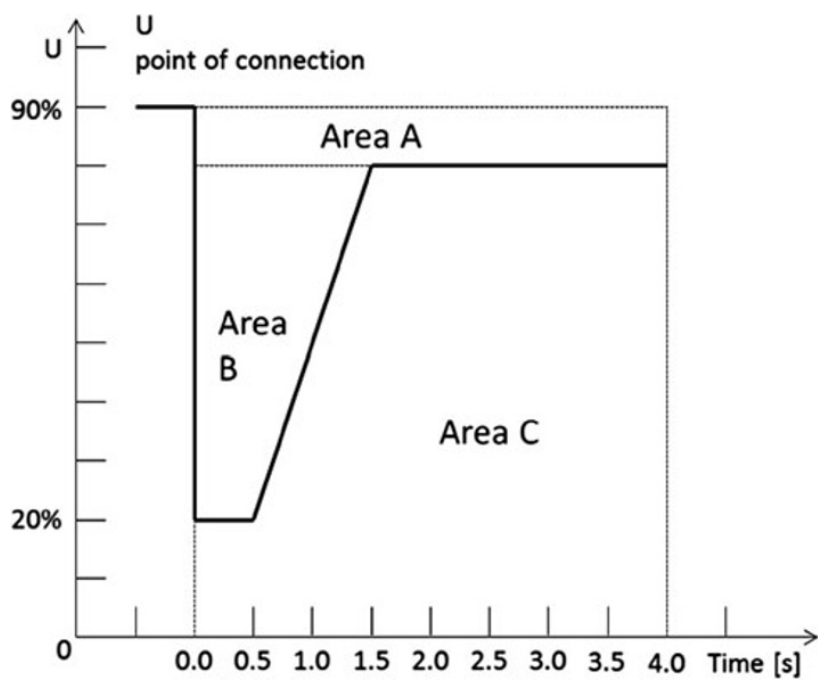

Fig. 7 LVRT requirements in Denmark [15]

of reactive power. For the wind farms established in Germany and Denmark, the basic requirements of power factor have been shown in Figs. 4-6. In Germany, when the voltage decreases from 170 to $140 \mathrm{kV}$, the power factor should vary from 0.95 unexcited to 0.925 overexcited [8, 16]. Moreover, the German grid code provides detailed requirements for individual wind turbine (as shown in Fig. 5). Besides, the operation regulations of power factor formulated by the TSOs in Canada, Ireland and China have been illustrated in Table 4.

The grid codes published in Canada, Ireland and China demand that WPPs provide the controllable reactive power depending on the supply of active power. It should be noted that the TSOs in some countries such as Germany and Denmark have provided specific requirements that the variation of reactive power production should depend on the change of voltage $[8,15,16]$. As presented in Fig. 4, these requirements are in terms of the relationship curves between voltage and power factor.

To implement the regulations above, the capability of WTs can be considered to be employed [8]. Besides, it is alternative to install extra reactive power source for WPPs [8]. In view of increasing integration level of wind energy, the specific control schemes, which aim at stabilizing grid voltage, can be investigated further. 


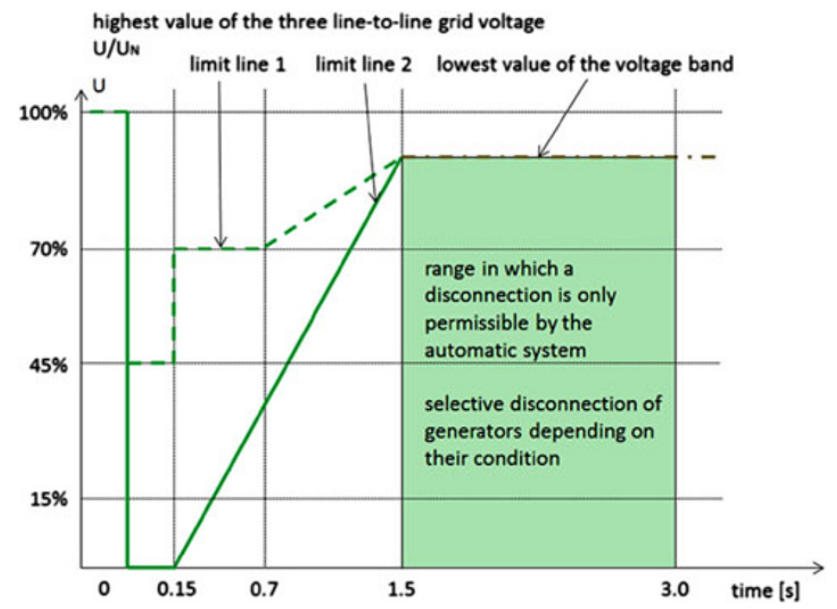

Fig. 8 LVRT requirements in Germany [16]

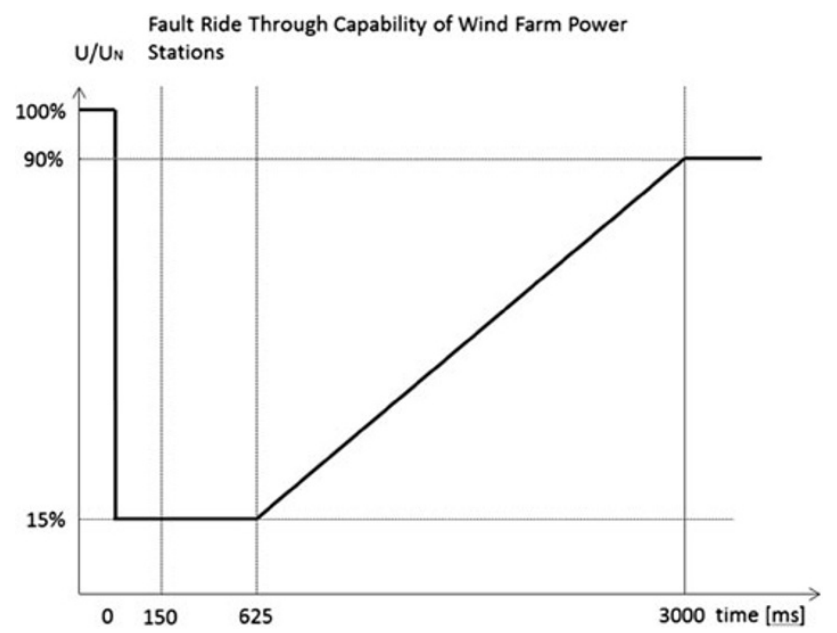

Fig. 9 LVRT requirements in Ireland [18]

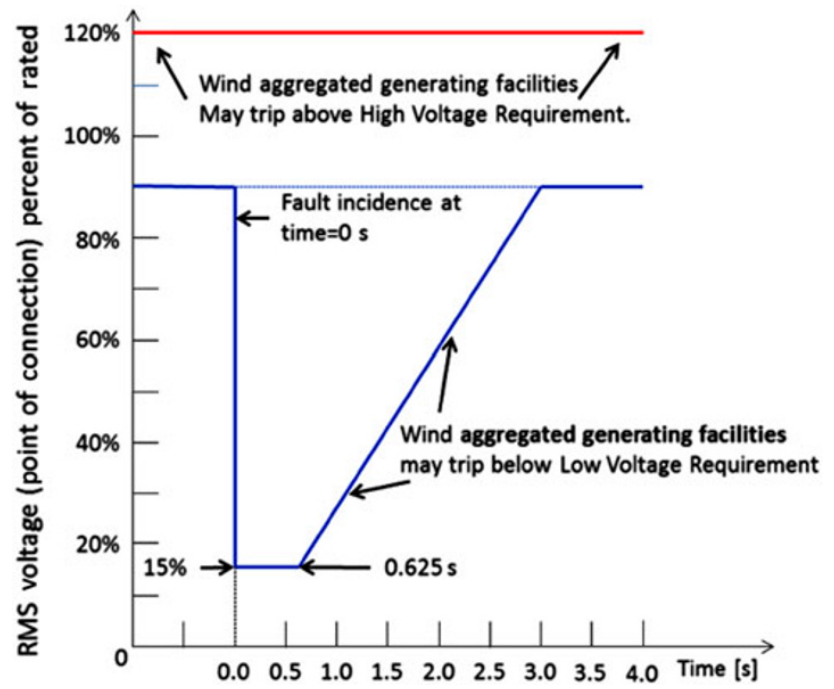

Fig. 10 LVRT requirements in Alberta, Canada [17]

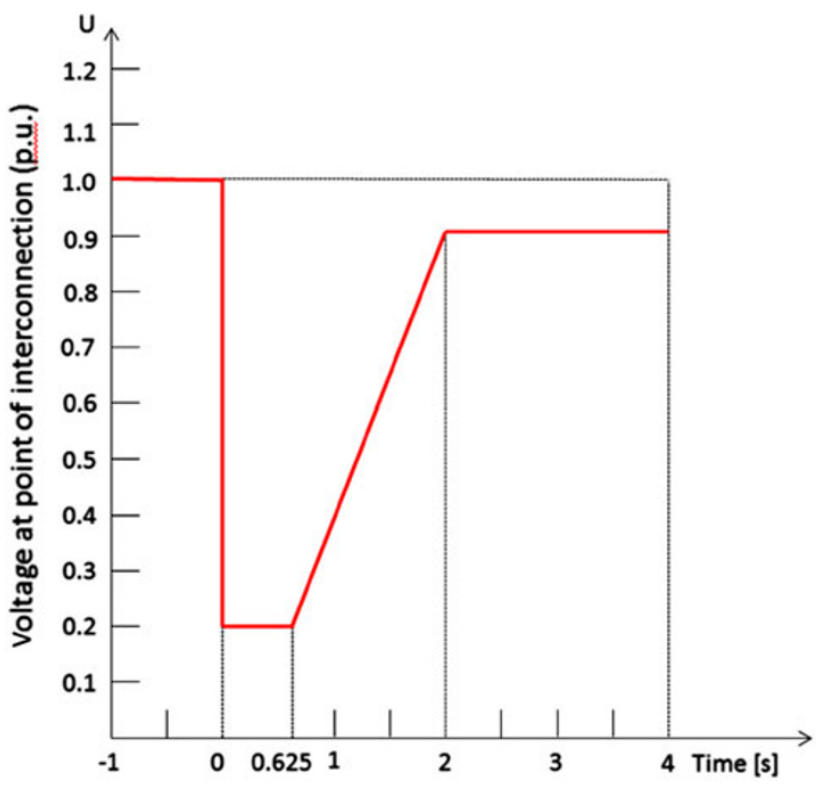

Fig. 11 LVRT requirements in China [19]

\section{Requirements of performance under fault condition}

\subsection{Requirements of LVRT}

When the penetration level of wind energy was quite low, the impact of wind generators was not considered by TSOs $[14,29]$. At that time, wind turbines were allowed to trip when grid faults occurred [29]. As the integration level of wind energy increases, the premature tripping of WTs may result in voltage collapse [30]. Therefore, the requirements of low voltage ride through, which demand that wind turbines should stay online rather than trip immediately when voltage sags, has been reinforced by TSOs [29]. The characteristics of LVRT in each country have been shown in Figs. 7-11.

The LVRT requirements of Denmark must be implemented in the case of faults of one, two or three phases. As shown in Fig. 7, the wind power plant must stay online in Area A. In Area B, the wind power plants should connect to the grid and provide reactive power for voltage support. Area $\mathrm{C}$ is the range that the wind power plants can be tripped [15]. As described in Figs. 9-11, the requirements of LVRT ability regulated in China, Ireland and Canada are similar [15-19].

The LVRT requirements of Germany, which is the most complicated, have been presented in Fig. 8. As the figure shows, the power system cannot become unstable above Limit Line 1. As for the area above the Limit Line 2, the wind power plants should keep on connecting to the grid. If a wind turbine becomes unstable, it can be self-disconnected from the grid [16]. 
$u$

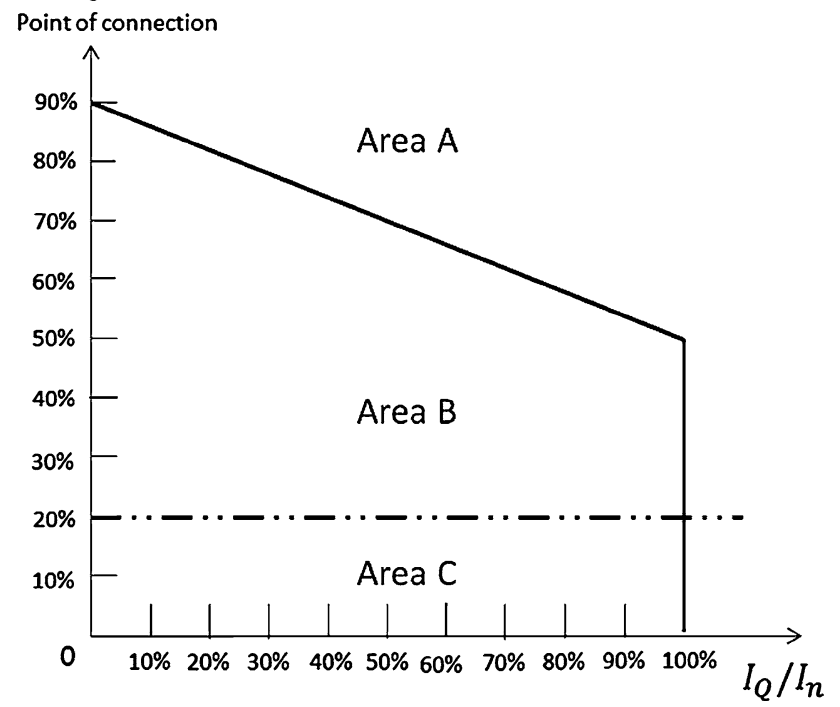

Fig. 12 Requirements of reactive current supply in Denmark [15]

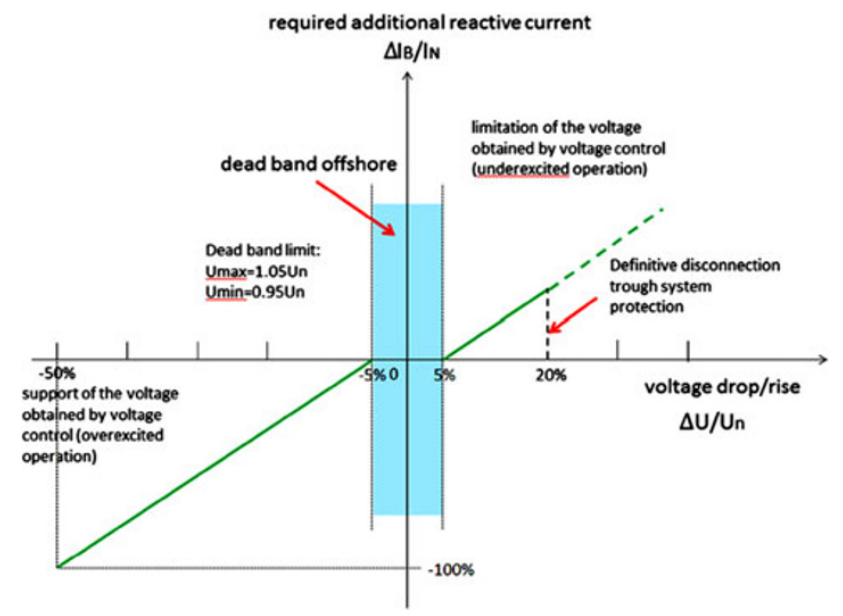

Fig. 13 Requirements of reactive current supply in Germany [16]

\subsection{Requirements of reactive current supply}

As analyzed in Section 2, FSWTs can hardly participate in voltage support. Since DFIGs have been widely installed recently, it is possible that the WPPs are able to provide available reactive current to enhance the stability of power system when grid faults occur [11].

Figures 12, 13 illustrate the requirements of reactive current supply in Denmark and Germany during the grid faults. Danish grid code demands that reactive current has a priority to be provided in Area B [15]. In Germany, wind turbines should provide reactive power no later than $20 \mathrm{~ms}$ after the voltage dip is detected [16].

Moreover, some countries such as Ireland encourage WPPs to generate active power during voltage dip $[13,18]$.
However, it should be observed that the demand of active power will decrease when the voltage sags. In order to avoid the occurrence of overcurrent in DFIGs, the active power production should be correspondingly reduced $[12$, 13]. Irish grid code claims that the value of active power provided by wind farm should be in proportion to the residual voltage under the faults [18].

When the voltage returns to normal range, the recovery rate of active power has been regulated in some grid codes so that the power surge can be avoided [24]. In Germany, the recovery rate should be between $10 \%$ and $20 \%$ of nominal power per second [16].

For individual DFIG, it is expected that the potential of reactive current supply can be exploited $[12,13]$. Several control schemes proposed that the capacitors and converters installed inside should be utilized to fulfill these requirements [13]. The schemes are promising to be applied in industry. By adopting the schemes, it is possible that DFIGs can be similar in performance to STATCOM during the low voltage. Moreover, it is necessary to note that both the situation of each WT and the wind condition should be considered when the schemes are implemented.

\section{Conclusions}

Modern power system has been influenced by the significant penetration level of wind energy. The impact of wind energy should be carefully analyzed and reconsidered [29].

In order to ensure the secure and economic operation of power system, TSOs in different countries have published various grid codes. In this paper, the basic requirements of grid codes have been discussed. Generally speaking, the grid code published by TenneT, which is a German TSO, formulates the most detailed technical requirements.

Considering the continuous growth of penetration level of wind energy, the requirements of grid codes should be reviewed and revised continuously [29]. Based on the paper, it is understood that grid integration requirements are recently strengthened in several respects such as reactive power control and LVRT to enhance the security of overall power system.

For manufactures and researchers, these grid codes can serve as important guidelines to develop new control strategies so that the performances of wind power plants can meet fulfill the ever changing requirements [6].

Open Access This article is distributed under the terms of the Creative Commons Attribution License which permits any use, distribution, and reproduction in any medium, provided the original author(s) and the source are credited. 


\section{References}

[1] International Energy Agency (2012) World energy outlook 2012. OECD/IEA, Paris

[2] Musunuri S, Ginn HL (2011) A fast maximum power extraction algorithm for wind energy systems. In: Proceedings of the 2011 IEEE Power and Energy Society general meeting(PES'11), Detroit, 24-29 July 2011, San Diego, CA, USA, p 7

[3] Gautam D, Vittal V, Harbour T (2009) Impact of increased penetration of DFIG-based wind turbine generators on transient and small signal stability of power systems. IEEE Trans Power Syst 24(3):1426-1434

[4] Singh B, Singh SN (2009) Wind power interconnection into the power system: a review of grid code requirements. Electr $\mathbf{J}$ 22(5):54-63

[5] Altın M, Göksu O, Teodorescu R et al (2010) Overview of recent grid codes for wind power integration. In: Proceedings of the 12th international conference on optimization of electrical and electronic equipment (OPTIM'10), Basov, Russia, 20-22 May 2010, pp 1152-1160

[6] Tsili M, Papathanassiou S (2009) A review of grid code technical requirements for wind farms. IET Renew Power Gener 3(3):308-332

[7] de Almeida RG, Peas Lopes JA (2007) Participation of doubly fed induction wind generators in system frequency regulation. IEEE Trans Power Syst 22(3):944-950

[8] Wu Q, Xu Z, Østergaard J (2010) Grid integration issues for large scale wind power plants (WPPs). In: Proceedings of the 2010 Power and Energy Society general meeting (PES'10),Minneapolis, 25-29 July 2010, p 6

[9] Tarnowski GC, Kjar PC, Sorensen PE et al (2009) Variable speed wind turbines capability for temporary over-production. In: Proceedings of the 2009 IEEE Power and Energy Society general meeting (PES'09), Calgary, Canada, 26-30 July 2009, p 7

[10] Chang-Chien LR, Lin WT, Yin YC (2011) Enhancing frequency response control by DFIGs in the high wind penetrated power systems. IEEE Trans Power Syst 26(2):710-718

[11] Ullah NR, Thiringer T, Karlsson D (2007) Voltage and transient stability support by wind farms complying with the E.ON netz grid code. IEEE Trans Power Syst 22(4):1647-1656

[12] Yang L, Xu Z, Østergaard J et al (2012) Advanced control strategy of DFIG wind turbines for power system fault ride through. IEEE Trans Power Syst 27(2):713-722

[13] Xie D, Xu Z, Yang L et al (2013) A comprehensive LVRT control strategy for DFIG wind turbines with enhanced reactive power support. IEEE Trans Power Syst 28(3):3302-3310

[14] Mohseni M, Islam SM (2012) Review of international grid codes for wind power integration: Diversity, technology and a case for global standard. Renew Sustain Energy Rev 16(6):3876-3890

[15] Technical regulation 3.2.5 for wind power plants with a power output greater than $11 \mathrm{~kW}$. 55986/10, Transmission System Operator of Denmark, Fredericia, Denmark, 2010

[16] Requirements for offshore grid connections in the grid of TenneT TSO GmbH. TenneT, Arnhem, Netherlands, 2012

[17] ISO rules, Part 500-Facilities, Division 502-Technical requirements, Section 502.1-Wind aggregated generating facilities, Technical requirements. Alberta Electric System Operator (AESO), 2013

[18] Grid code version 4.0. EirGrid, Dublin, Ireland, 2012

[19] GB/T 19963-2011 Technical rule for connecting wind farm to power network (in Chinese)

[20] Hansen AD, Sørensen P, Iov F et al (2006) Centralised power control of wind farm with doubly fed induction generators. Renew Energy 31(7):935-951

[21] Moon SI, Pyo GC, Park JW (2010) Study on development of grid code and operation scheme of Jeju Island with high wind penetration. In: Proceedings of the 21 st world energy congress, Montréal, Canada, 12-16 Sept 2010

[22] Howlader AM, Urasaki N, Yona A et al (2013) A review of output power smoothing methods for wind energy conversion systems. Renew Sustain Energy Rev 26:135-146

[23] Uehara A, Pratap A, Goya T et al (2011) A coordinated control method to smooth wind power fluctuations of a PMSG-based WECS. IEEE Trans Energy Convers 26(2):550-558

[24] Jauch C (2006) Stability and control of wind farms in power systems. Ph.D. Dissertation, Aalborg University, Aalborg, Denmark

[25] Domínguez T, de la Torre M, Juberías G et al (2008) Renewable energy supervision and real time production control in Spain. In: Proceedings of the international conference on renewable energies and power quality (ICREPQ'08), Santander, Spain, 12-14 Mar 2008, p 6

[26] Hansen AD, Hansen LH (2007) Market penetration of wind turbine concepts over the years. In: Proceedings of the European wind energy conference and exhibition (EWEC'07), Milan, Italy, 7-10 May 2007, p 6

[27] Akhmatov V (2005) Induction generators for wind power. Multi-Science Publishing Co Ltd, Brentwood

[28] Specifications for connecting wind farms to the transmission network. ELT 1999-411A, 2nd edn. ELTRA, Copenhagen, Denmark, 2000

[29] Abbey C, Joos G (2005) Effect of low voltage ride through (LVRT) characteristic on voltage stability. In: Proceedings of the 2005 IEEE Power Engineering Society general meeting (PES'10), vol 2, San Francisco, 12-16 Jun 2005, pp 1901-1907

[30] Arulampalam A, Ramtharan G, Jenkins N et al (2007) Trends in wind power technology and grid code requirements. In: Proceedings of the 2nd international conference on industrial and information systems (IIS’07), Peradeniya, Sri Lanka, 8-11 Aug 2007, pp 129-133

\section{Author Biographies}

Xiaoge LIU received his B.Eng. from Huazhong University of Science and Technology, Wuhan, China 2012. He is now an M.Phil. candidate with The Hong Kong Polytechnic University.

Zhao XU received his B.Eng., M.Eng., and Ph.D. degrees from Zhejiang University, China, in 1996, National University of Singapore, Singapore, in 2002, and The University of Queensland, Australia, in 2006, respectively. He is now with The Hong Kong Polytechnic University. He was previously an Associate Professor with Centre for Electric Power and Energy, Technical University of Denmark. His research interest includes demand side, grid integration of renewable energies and EVs, electricity market planning and management, and AI applications in power engineering. He is an Editor of Electric Power Components and Systems journal.

Kit Po WONG received the M.Sc, Ph.D., and higher doctorate D.Eng. degrees from the University of Manchester, Institute of Science and Technology, Manchester, UK, in 1972, 1974, and 2001, respectively. He is a Fellow of IEEE. Since 1974, he has been with the School of Electrical, Electronic and Computer Engineering, The University of Western Australia, where he is currently a Winthrop Professor. His current research interests include power system analysis, planning and operations, and smart grids. Prof. Wong received three Sir John Madsen Medals (1981, 1982, and 1988) from the Institution of Engineers Australia, the 1999 Outstanding Engineer Award from IEEE Power Chapter Western Australia, and the 2000 IEEE Third Millennium Award. He was General Chairman of IEEE/ CSEE PowerCon2000 conference. He was an Editor-in-Chief of IEE Proceedings in Generation, Transmission and Distribution. Currently he is serving as Editor-in-Chief for IEEE Power Engineering Letters of the IEEE PES Transactions. 